\title{
TRAMADOL AS ADJUNCT TO EPIDURAL CAUDAL ANESTHESIA IN PEDIATRIC PATIENTS
}

\author{
Dario Galante, MD \\ Department of Anesthesia and Intensive Care \\ University Hospital Ospedali Riuniti, Foggia, Italy
}

\section{Introduction}

Tramadol as adjunct to local anaesthetics may be used for caudal epidural analgesia and is effective with minimal side effects or complications. This study was performed to evaluate its analgesic, efficacy and safety in pediatric patients undergoing inguinal hernia repair.

\section{Materials and Methods}

After IRB ethical approval 66 children aged between one and 5 years undergoing inguinal hernia repair were randomized to receive either a caudal epidural injection of Levobupivacaine $(1 \mathrm{ml} / \mathrm{kg}$ of $0.25 \%$ ) alone (group L), or with $2 \mathrm{mg} / \mathrm{kg}$ of Tramadol (group T) plus sevoflurane sedation in air and $\mathrm{O}_{2}$. During the postoperative time to first analgesia, number of doses of paracetamol administered within the first 24 hours, sedation scores within the first hour, and time to home readiness were recorded.

\section{Results}

The mean time to first rescue dose for analgesic was significantly longer $(123=0.0003)$ in group $T(459.52 \mathrm{~min} \pm$ $48.43 \mathrm{~min}$ ) compared to group $L(224.65 \mathrm{~min} \pm 41.00 \mathrm{~min})$. The number of rescue doses of post-operative analgesic administered was significantly lower in the study group ( $p=$ 0.0002). Sedation scores were similar in the first hour post operatively. No hemodynamic changes or respiratory complications were observed.

\section{Conclusion}

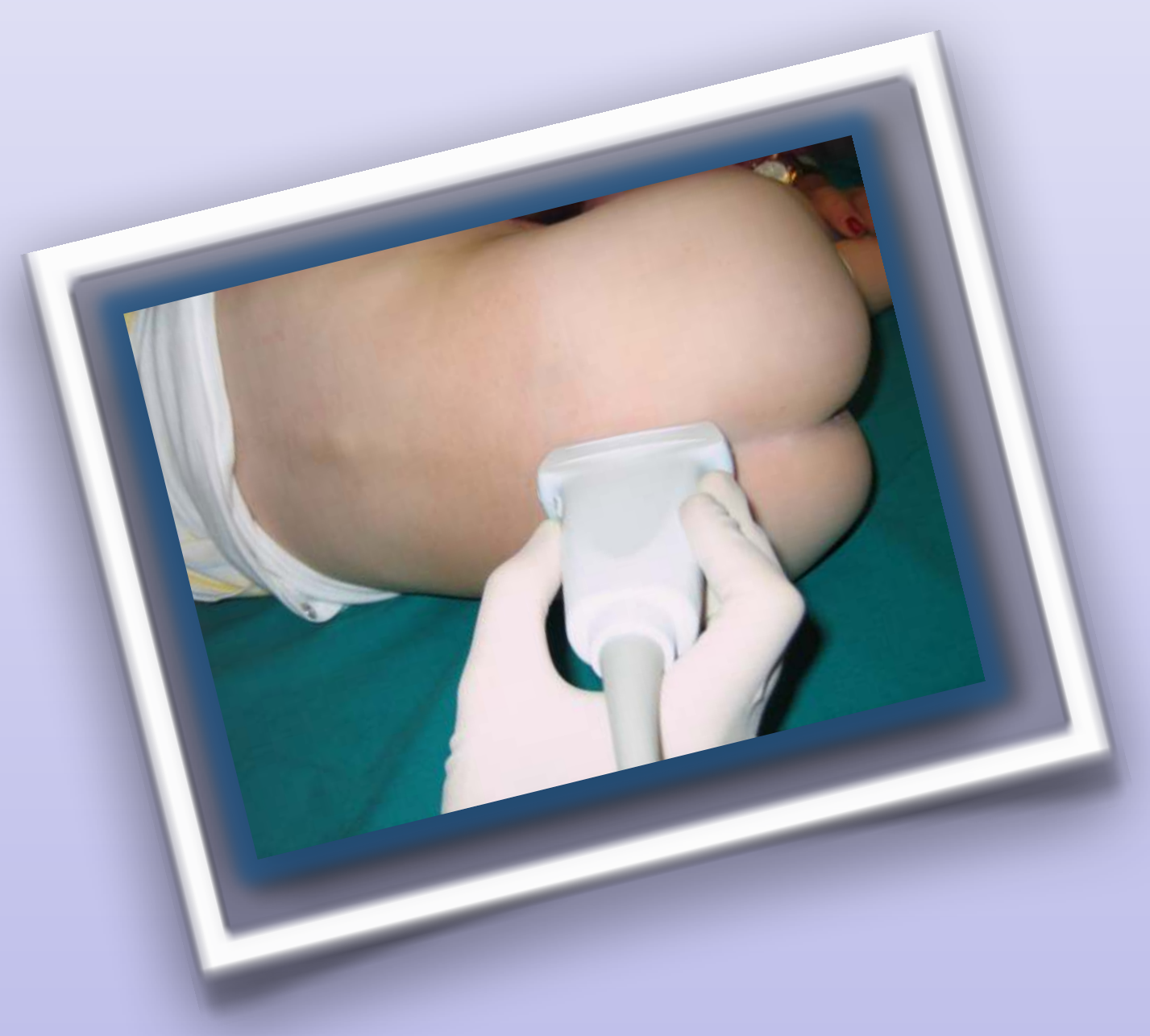

This study demonstrated that caudal levobupivacaine and tramadol injection provided longer duration of analgesia in children undergoing inguinal hernia repair procedures compared to bupivacaine alone with satisfactory recovery profile.

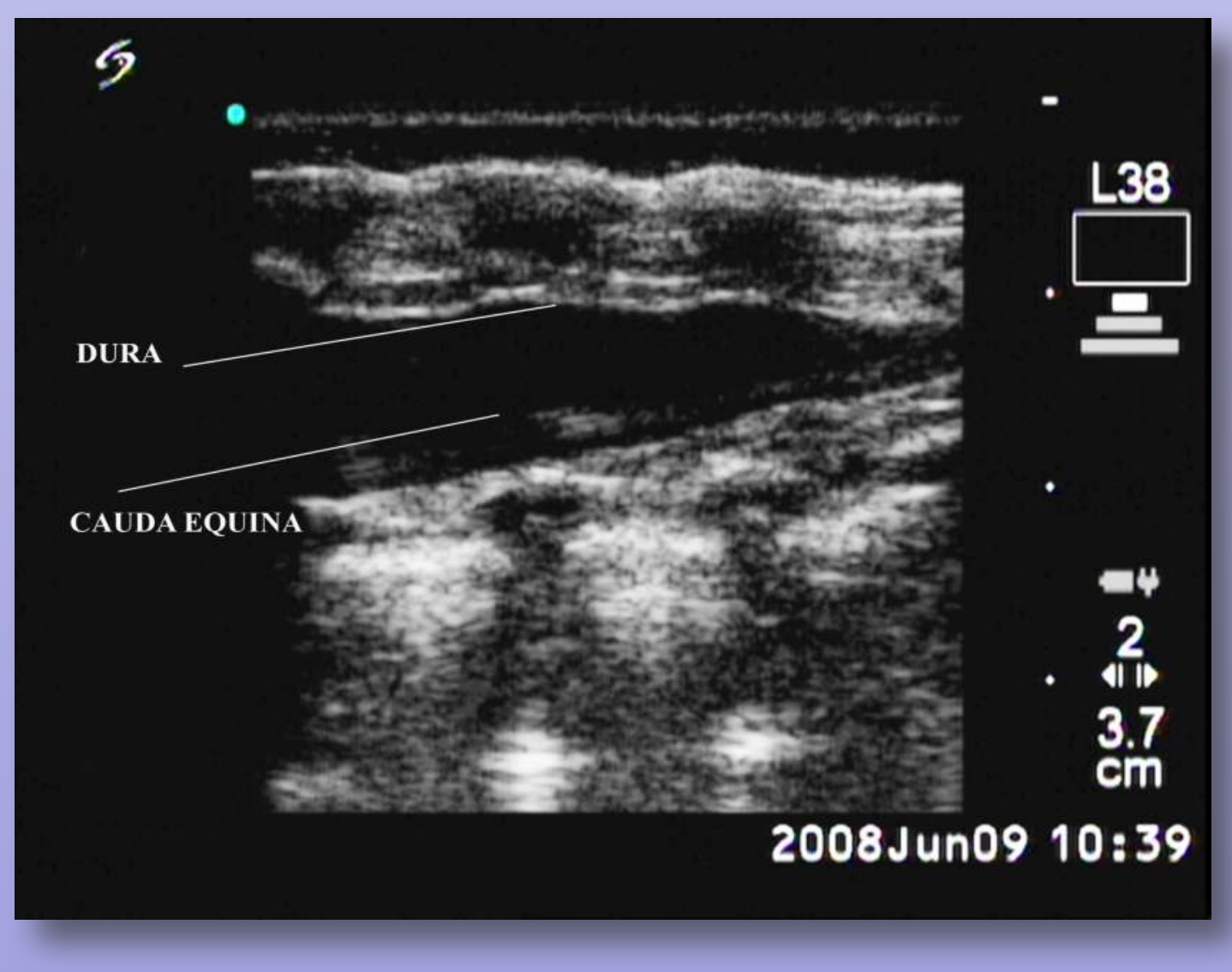

Ultrasound caudal block
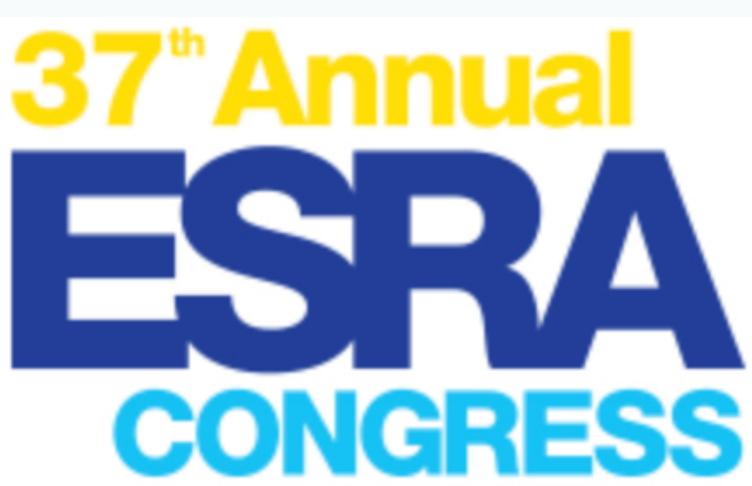

DUBLIN, IRELAND

12-15 SEPTEMBER 2018

We invite you to:

The Three Maternal Infant Days

International Congress on Obstetric and Pedaitric Emergencies

Foggia, Italy, 18-20 October, 2018

Flyer SIAATIP website: http://www.siaatip.it/

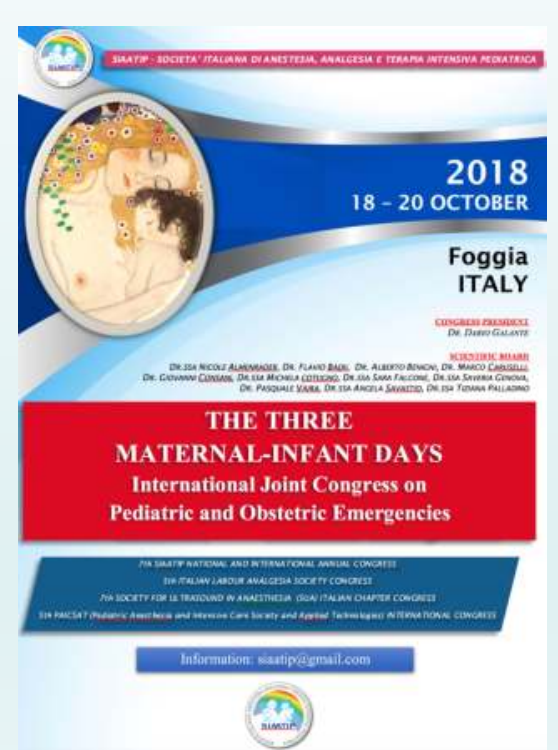

